\title{
At Amherst and Afterwards: Interview with Tyler Abell About Don Lindberg
}

\author{
Robert A. LOGAN Ph.D. ${ }^{1}$ \\ U.S. National Library of Medicine (retired)
}

Keywords: Donald A. B. Lindberg M.D., Amherst College, Oscar E. Schotte

The Orange Blossom Group formed during Don Lindberg's sophomore year - when he lived with several roommates in a three-bedroom suite at Amherst College. Orange Blossom was the Group's Sunday beverage of choice - a concoction of gin, vermouth, and orange juice. (Dr. Lindberg eventually preferred bourbon).

In a summer 2020 interview, Tyler Abell described the Orange Blossom Group's life-long friendship and added a few insider tales. For example, some Orange Blossom members were airplane pilots. Don took flying lessons and received a pilot's license in college. If an Orange Blossom Group member flew on Sunday, he was a temporary teetotaler.

Dr. Lindberg stood out within the Group because: 'Don loved science .... and he looked younger than most of us,' Abell said. After graduating from Amherst, Abell became an attorney and was the Chief of Protocol for the U.S. during the Johnson administration. The Lindbergs and Abells lived near each other in suburban Maryland after Don arrived as the National Library of Medicine's director in 1984.

Abell noted how much the then-teenage Lindberg enjoyed working with Amherst embryologist Dr. Oscar Schotte. Abell explained it was somewhat unusual for students to become close to Amherst professors in their underclassmen years. After all, Amherst's faculty included poet Robert Frost.

Yet, Don (who once scored a perfect 100 on a challenging course exam) regarded Schotte as a mentor almost immediately. Outside of family members, Schotte remained one of Dr. Lindberg's enduring influences, Abell explained.

Recalling a few exploits from a more innocent era, Abell said Don once arrived a half-day late for a Washington year-end visit and forgot to bring a tuxedo needed to attend holiday events.

Although most of the Orange Blossom Group enjoyed music, Don again stood out because he loved opera. The latter was problematic because his enthusiasm was unrequited - and there was only one place to play records inside the Group's suite. Even worse, some of Don's opera records and their packaging were irregularly sized and could scratch other recordings if placed on top or next to them.

Yet before quarrels emerged, a clever roommate built a case where $78 \mathrm{~s}$ and LPs could slide into a groove space, and the individual records and their cases did not touch each other. 'Even the opera and Benny Goodman records fit,' Abell exclaimed. (Some recordings of the Goodman band were distributed in cases that were as difficult to store as operas).

\footnotetext{
${ }^{1}$ Corresponding author: logrob@gmail.com
} 
So, although Don's roommates may not have been enamored with Don Giovanni, diva-like disputes and disruptions never erupted.

More seriously, Abell explained each member of the Orange Blossom Group was challenged by the possibility of military service in the Korean War. Like most male college students in the early-1950s, each Group member possessed a draft card they received at age 18. 'Initially, we worried if we would even be able to go to college and later whether we would be able to graduate,' Abell said.

While the Korean War provided a constant reminder about everyone's vulnerability, Abell noted that living with uncertainty helped bring the Group together and intensified how college students perceived their broader social responsibilities. In addition to Abell and Lindberg, the subsequent careers of other Group members featured public service and charitable work.

While separated by geography, the Orange Blossom Group members remained concerned about each other's health and welfare long after they graduated from Amherst. Abell said Dr. Lindberg took the time to assist Group members to find physicians for themselves or family members. Abell also noted when one of the Group members became seriously ill in late middle age, others (including Dr. Lindberg) rallied successfully to help him find better medical care and remain upbeat.

Regarding Dr. Lindberg's growth and interests, Abell suggested many of Don's hobbies (including travel, boating, opera, reading, collecting books and music, photography, technology, and interest in science and the humanities) were formed by his 21 st birthday.

Abell added Don's curiosity about Washington's inner workings might have been influenced by occasional visits with Drew Pearson, a legendary Washington insider columnist who was Abell's stepfather. In later years, Dr. Lindberg's exposure to Washington protocols was boosted by Bess Abell, Tyler's wife and First Lady Lady Bird Johnson's social secretary. The late Ms. Abell later ran Bess Abell Enterprises, a wellconnected Washington public relations firm.

Of course, it helped that Mary Lindberg (Don's wife) grew up in Washington and was reasonably comfortable with the city's cognoscenti and social norms, Abell explained.

Meanwhile, Dr. Lindberg's ability to lead was an accumulation of experiences, interests, counsel, access, energy, intelligence, and perseverance, Abell said. While the Orange Blossom Group may not have Don's life and career, its members encouraged his curiosity and wide range of interests early on and throughout his life. 